\title{
New Somatic Hybrid Mandarin Tetraploids Generated by Optimized Protoplast Fusion and Confirmed by Molecular Marker Analysis and Flow Cytometry
}

\author{
Milica Calović \\ University of Florida, Institute of Food and Agricultural Sciences, Citrus Research and Education \\ Center, 700 Experiment Station Road, Lake Alfred, FL 338507 \\ Chunxian Chen \\ U.S. Department of Agriculture, Agricultural Research Service, Southeastern Fruit and Tree Nut \\ Research Laboratory, 21 Dunbar Road, Byron, GA 31008 \\ Qibin Yu, Vladimir Orbović, Frederick G. Gmitter Jr., and Jude W. Grosser ${ }^{1}$ \\ University of Florida, Institute of Food and Agricultural Sciences, Citrus Research and Education \\ Center, 700 Experiment Station Road, Lake Alfred, FL 338507
}

\begin{abstract}
Additional INDEX words. breeding, citrus, interploid cross, tissue culture
Abstract. Six mandarin cultivars, Ponkan (Citrus reticulata), Willowleaf (Citrus deliciosa), Kinnow (Citrus nobilis $\times$ C. deliciosa), Murcott (purported $C$. reticulata $\times$ Citrus sinensis), W. Murcott [purported (C. reticulata $\times$ C. sinensis) $\times$ C. reticulata)], and Snack (purported $C$. reticulata hybrid), were used in protoplast fusion with different parental combinations to generate somatic hybrids. Sixty-five somatic regenerants were obtained using optimized formulation of enzymes and molecular weight of polyethylene glycol for improved protoplast yield and heterokaryon fusion rate, respectively. Flow cytometry was used to determine the ploidy level of somatic regenerants, and nuclear expressed sequence tag-simple sequence repeat (EST-SSR) markers to determine their parental source. Of the 65 somatic regenerants, 46 were identified as autotetraploids, 18 allotetraploids, and one undefined. The EST-SSR markers also revealed that some 'W. Murcott' embryogenic callus lines that were presumed to be of nucellar origin were actually derived unexpectedly from individual ovules of zygotic origin. These mandarin-derived tetraploids are valuable as potential breeding parents for interploid crosses with an aim at seedlessness and easy-peeling traits.
\end{abstract}

Development of improved cultivars through conventional hybridization in mandarins has been hampered by several characteristics of their reproductive biology, mainly apomixis (nucellar polyembryony), sexual incompatibility, and long juvenility. Moreover, most conventional diploid hybrids produce seedy fruit, which is not well accepted in the fresh citrus (Citrus sp. and hybrids) marketplace. Triploid hybrids are generally sterile and usually produce seedless or low-seeded fruit, which has been a primary objective of mandarin breeding programs (Frost and Soost, 1968). Thus, triploid cultivars can be safely planted adjacent to other diploid cultivars like clementine that produce seedless fruit when not cross-pollinated. Specific conventional diploid crosses can generate a low percentage of triploid progeny, if the female parent can reliably produce unreduced gametes. This type of cross has been successfully used to develop the commercially released seedless triploid mandarin cultivars Garbi [(Citrus clementina $\times C$. reticulata $) \times(C$. reticulata $\times C$. sinensis $)($ Aleza et al., 2010)] and Safor $[(C$. clementina $\times$ C. reticulata $) \times($ Citrus unshiu $\times C$. nobilis) (Cuenca et al., 2010)]. As an alternative, the combination of two unconventional methods, somatic hybridization via protoplast fusion and interploid sexual hybridization, has become an integral part of mandarin cultivar improvement

Received for publication 10 Oct. 2018. Accepted for publication 20 Feb. 2019. ${ }^{1}$ Corresponding author. E-mail: jwg@ufl.edu. programs targeting seedlessness worldwide, because they can easily overcome some mentioned biological or reproductive limitations (Aleza et al., 2016; Grosser and Gmitter, 2011; Grosser et al., 2010a, 2010b; Guo et al., 2018; Ollitrault et al., 2007). Interploid hybridization of diploids with autotetraploids created by various methods has resulted in a few commercial seedless triploid hybrids in citrus. These include grapefruitlike pummelo hybrids 'Oroblanco' and 'Melogold' [Citrus grandis $\times$ Citrus paradisi (Soost and Cameron, 1980, 1985)] and seedless mandarin hybrid 'Tacle' from a cross of 'Monreal' clementine (C. clementina) with autotetraploid 'Tarocco' blood orange [C. sinensis (Starrantino, 1999)]. In our program, two seedless triploid hybrids produced by this method are currently being commercialized. They are UF-914 (PP 26177), which is a very high-quality red grapefruit-like hybrid from a cross of 'Siamese Sweet' pummelo (C. grandis) with autotetraploid 'Ruby Red' grapefruit (C. paradisi); and RBB 7-34 (Plant Patent pending), which is a very high-quality 'Navel' sweet orange (C. sinensis)-like hybrid from a cross of 'LB8-9' SugarBelle $^{\circledR}[C$. clementina $\times(C$. reticulata $\times C$. paradisi $)]$ with autotetraploid 'Hamlin' sweet orange.

By using somatic hybridization, it is possible to produce novel germplasm at the tetraploid level that combines many good qualities of fused diploid selections. We have used this technique to greatly expand the tetraploid germplasm available for interploid crosses (Grosser et al., 2010a, 2010b). Used 
further in interploid sexual hybridization, these newly produced somatic tetraploid hybrids (crossed with selected diploid breeding parents) can efficiently generate triploid hybrids from many more parental combinations. Besides seedlessness, there are other important breeding objectives for mandarins: easypeel fruit, extension of the season of availability (early and late), improved flavor, juice quality, shelf life, cold hardiness, and disease resistance. In our program, we have produced numerous seedless triploid mandarin hybrids, including several that have outstanding flavor; however, most of these are not easy to peel. The first seedless triploid hybrid fathered by a somatic hybrid to be commercialized from our program is $\mathrm{C} 4$ 15-19 (PP 26086; a delicious fruit with high sugar content produced from an interploid cross of 'LB8-9' SugarBelle ${ }^{\circledR}$ with the 'Nova'+'Succari' sweet orange somatic hybrid $\{C$. clementina $\times[(C$. reticulata $\times C$. paradisi $)+C$. sinensis $]\}$. Although fruit of this productive hybrid can be peeled, it is not considered "zipper skinned." The goal of this project was to optimize the method of protoplast fusion to create tetraploid parents that could be used in breeding for production of the high-quality triploid cultivars with the "easy-peel" characteristic as found in W. Murcott and Ponkan.

\section{Materials and Methods}

COLleCtion OF EXPLANTS FOR PROTOPLAST ISOlation. Plant material used in all experiments was taken from mature trees grown at two locations in central Florida: Florida Department of Citrus Industry (Winter Haven), and Citrus Research and Education Center (Lake Alfred). Embryogenic callus lines of 'Ponkan' mandarin, 'Page' tangelo [(C. reticulata $\times C$. paradisi) $\times$ C. clementina], 'Murcott' and 'W. Murcott' tangors [a zygotic seedling derived from 'Murcott'] were induced from undeveloped ovules and used as the callus parents. Ovules were extracted in aseptic conditions from 3- to 5-month-old fruit.

Nonembryogenic protoplasts used as the leaf parents were isolated from leaves of in vitro-grown plants germinated from seeds of the following cultivars: Willowleaf mandarin, Ponkan mandarin, Kinnow mandarin, Snack mandarin hybrid, W. Murcott tangor, and Osceola tangelo [C. clementina $\times$ (C. reticulata $\times C$. paradisi)]. Plants were maintained on RMAN medium (Grosser and Gmitter, 1990) in Magenta vessels (GA-7; Magenta, Lockport, IL) and subcultured every 2 to 3 months to have a continuous source of tender expanding sterile leaves.

INITIATION AND MAINTENANCE OF EMBRYOGENIC CALLUS AND SUSPENSION CULTURES. After extraction, ovules were placed on callus induction medium, incubated in the darkness at $28 \pm$ $2{ }^{\circ} \mathrm{C}$, and transferred onto fresh plates every 2 to 3 weeks until the appearance of friable nucellus-derived embryogenic callus. To find the most efficient callus induction medium, ovules were incubated on $0.15 \mathrm{M}$ EME callus induction/maintenance medium (Grosser et al., 2010b) supplemented with $50 \mathrm{~g} \cdot \mathrm{L}^{-1}$ sucrose $(0.15 \mathrm{M}), 0.25 \mathrm{~g} \cdot \mathrm{L}^{-1}$ malt extract, $8 \mathrm{~g} \cdot \mathrm{L}^{-1}$ agar, and three different concentrations of kinetin: $0,0.5$, and $10.0 \mathrm{mg} \cdot \mathrm{L}^{-1}$. Each treatment consisted of three replicates with a total of 190 to 610 ovules. Both callogenesis and embryogenesis of ovules were recorded once per month during the period of 9 consecutive months (after initial placing of ovules on callus induction medium) as the percentage of ovules that produced callus and/ or nucellar embryos, respectively. Statistical analysis of the effect of genotype and kinetin concentration on callogenesis and embryogenesis from ovules was done by using Duncan multiple range test (Duncan, 1955) at $P<0.05$.

Nucellus-derived embryogenic callus was further maintained in petri dishes $(100 \times 15 \mathrm{~mm})$ on $\mathrm{H}+\mathrm{H}$ medium (Grosser et al., 2010b) supplemented with $50 \mathrm{~g} \cdot \mathrm{L}^{-1}$ sucrose $(0.15 \mathrm{M}), 0.5$ $\mathrm{g} \cdot \mathrm{L}^{-1}$ malt extract, $1.55 \mathrm{~g} \cdot \mathrm{L}^{-1}$ glutamine, and $8 \mathrm{~g} \cdot \mathrm{L}^{-1}$ agar. Proliferating friable callus was subcultured every 4 weeks and kept in the darkness at $28 \pm 2{ }^{\circ} \mathrm{C}$ before initiation of suspension cultures. Calli derived from different ovules were mixed and maintained together except when used for the additional ESTSSR analysis when callus derived from each ovule was kept as a separate line. During the maintenance phase of the callus, differentiated tissues, organs, and whole somatic embryos (which were appearing directly from the callus cells with high embryogenic potential) were regularly discarded through visual selection to maintain the callus in an undifferentiated state as a prerequisite for successful establishment of suspension cultures.

Suspension cultures were initiated by transferring $\approx 2 \mathrm{~g}$ of callus tissue to a $125-\mathrm{mL}$ erlenmeyer flask containing $20 \mathrm{~mL}$ $\mathrm{H}+\mathrm{H}$ liquid medium supplemented with $35 \mathrm{~g} \cdot \mathrm{L}^{-1}$ sucrose $(0.1 \mathrm{M}), 0.5 \mathrm{~g} \cdot \mathrm{L}^{-1}$ malt extract, and $1.55 \mathrm{~g} \cdot \mathrm{L}^{-1}$ glutamine. Cultures were shaken continuously on a rotary shaker (125 rpm) and incubated at $28 \pm 2{ }^{\circ} \mathrm{C}$ with a 16-h photoperiod $\left(70 \mu \mathrm{mol} \cdot \mathrm{m}^{-2} \cdot \mathrm{s}^{-1}\right)$. After 2 weeks, another $20 \mathrm{~mL}$ of $\mathrm{H}+\mathrm{H}$ liquid medium was added to each flask to bring the total volume to $40 \mathrm{~mL}$. Rapidly growing suspension cultures were subcultured every 2 weeks before protoplast isolation.

ENZYMATIC DIGESTION OF EMBRYOGENIC CELL SUSPENSION AND IN VITRO-GROWN LEAVES. Approximately $2 \mathrm{~mL}$ (correlates to $1 \mathrm{~g}$ fresh weight) of embryogenic cell suspension was transferred into a petri dish $(60 \times 15 \mathrm{~mm})$. The excess $\mathrm{H}+\mathrm{H}$ liquid medium was removed with a Pasteur pipette, and the remaining tissue was resuspended in a 2.5:1.5 (v:v) mixture of $0.6 \mathrm{M} \mathrm{BH3}$ liquid medium (Grosser et al., 2010b) and enzyme solution. For purification of protoplasts from a nonembryogenic source, 10 to 15 sterile leaves (correlates to $1-2 \mathrm{~g}$ fresh weight) from in vitro-grown nucellar seedlings were used. They were cut into 1- to 2-mm-wide segments with a sterile surgical blade and incubated in a 125-mL erlenmeyer flask containing an 8:3 (v:v) mixture of $0.6 \mathrm{M} \mathrm{BH} 3$ protoplast culture medium and enzyme solution. Enzyme digestion of leaves was maximized by application of vacuum for 20 to $30 \mathrm{~min}$ at $50 \mathrm{kPa}$. Preparations of both cell suspension tissue and leaf segments were incubated overnight $(15-20 \mathrm{~h})$ at $28 \pm 2{ }^{\circ} \mathrm{C}$ on a rotary shaker at $50 \mathrm{rpm}$ in the dark.

For release and purification of protoplasts from the two parental sources (embryogenic cell suspension and nonembryogenic in vitro-grown leaves), three different formulations of enzyme solution were used: A: $1 \%$ cellulase, $1 \%$ macerase, $0.2 \%$ pectolyase, $0.7 \mathrm{M}$ mannitol, $24 \mathrm{~mm} \mathrm{CaCl}_{2} \times 2 \mathrm{H}_{2} \mathrm{O}$, $6.15 \mathrm{~mm}$ MES buffer, $0.92 \mathrm{~mm} \mathrm{NaH} \mathrm{PO}_{4}, \mathrm{pH}=5.6$. B: $1 \%$ cellulase, $1 \%$ macerase, $0.7 \mathrm{M}$ mannitol, $24 \mathrm{mM} \mathrm{CaCl}_{2} \times 2 \mathrm{H}_{2} \mathrm{O}$, 6.15 mM MES buffer, $0.92 \mathrm{~mm} \mathrm{NaH}_{2} \mathrm{PO}_{4}, \mathrm{pH}=5.6$. C: $2 \%$ cellulase, $2 \%$ macerase, $0.7 \mathrm{M}$ mannitol, $24 \mathrm{mM} \mathrm{CaCl}_{2} \times 2 \mathrm{H}_{2} \mathrm{O}$, 6.15 mM MES buffer, $0.92 \mathrm{~mm} \mathrm{NaH}_{2} \mathrm{PO}_{4}, \mathrm{pH}=$ 5.6. All enzymes used in these mixtures were manufactured by Yakult Honsha Co., Tokyo, Japan (cellulase = Cellulase Onozuka RS, macerase $=$ Macerozyme R10, pectolyase $=$ Pectolyase Y23).

Protoplast isolation AND FUSion. Following overnight incubation, enzymatic preparations from two parental sources were passed through a sterile nylon mesh sieve $(45-\mu \mathrm{m}$ pore size) to remove undigested tissues. Final isolation of viable 
protoplasts was achieved by centrifugation on a $25 \%$ sucrose13\% mannitol gradient (Grosser and Gmitter, 1990). Isolated protoplasts were resuspended separately in appropriate volume of $0.6 \mathrm{M} \mathrm{BH} 3$ liquid medium in the concentration of 3 to $5 \times 10^{6}$ protoplasts $/ \mathrm{mL}$. Isolated protoplasts were counted on a hemocytometer. Their concentration was expressed as the number of live protoplasts that could be obtained from $1 \mathrm{~g}$ of leaf fresh weight. Each treatment with different enzyme solution consisted of three replicates.

Protoplasts from two sources were mixed together in a 15-mL calibrated screw-top centrifuge tube at a ratio of $1: 1$. Protoplast fusion was carried out by the "chemical" method based on the use of polyethylene glycol (PEG) described by Grosser and Gmitter (1990). In this method, 4 to 5 drops (correlates to $0.5-1 \times 10^{6}$ protoplasts) of mixed protoplasts were carefully placed with a Pasteur pipette in the center of petri dish $(60 \times 15 \mathrm{~mm})$. To induce fusion, 4 to 5 drops of $40 \%$ $(\mathrm{w} / \mathrm{v})$ PEG solution were placed over the protoplast mixture allowing the PEG to mix with protoplasts. The effect of molecular mass $(\mathrm{MM})$ of PEG $(\mathrm{MM}=1500,6000$, and 8000$)$ on the production of somatic hybrids was tested. Each experiment consisted of three to five replicates and each replicate was conducted in six to eight petri dishes. After elution with highly alkaline $(\mathrm{pH}=10.5) \mathrm{A}+\mathrm{B}$ solution, fusing protoplasts were rinsed by using $0.6 \mathrm{M} \mathrm{BH} 3$ liquid medium. Final incubation was done in a thin layer of 1.5 to $2.0 \mathrm{~mL}$ of $1: 1(\mathrm{v}: \mathrm{v})$ mixture of $0.6 \mathrm{M} \mathrm{BH}$ and 0.6 M EME liquid media. Medium 0.6 M EME is $0.15 \mathrm{M}$ EME basal medium supplemented with $205.38 \mathrm{~g} \cdot \mathrm{L}^{-1}$ sucrose $(0.6 \mathrm{M})$. All petri dishes were sealed with parafilm (Bemis Co., Neenah, WI) and cultured in the dark at $28 \pm 2{ }^{\circ} \mathrm{C}$ for 4 to 6 weeks.

Protoplast culture and Plant regeneration. Microcolony formation occurred spontaneously from cultivated protoplasts after their initial plating in a thin layer (Fig. 1). Formed colonies were supplied with 10 to 15 drops of a reduced osmoticum 1:1:1 (v:v:v) mixture of $0.6 \mathrm{M} \mathrm{BH3,} 0.6 \mathrm{M} \mathrm{EME,}$ and $0.15 \mathrm{~m}$ EME liquid media (Grosser et al., 2010b) to induce their maturation. Afterward, to further induce embryogenesis from colonies, the cultures were exposed to additional reduction of osmoticum. A 1:2(v:v) mixture of $0.6 \mathrm{M} \mathrm{BH3}$ and $0.15 \mathrm{M}$ EME liquid media in volume of 2 to $3 \mathrm{~mL}$ was added to each plate. The content of plates was then poured into petri dishes $(100 \times 20 \mathrm{~mm})$ over agar-solidified $0.15 \mathrm{M}$ EME medium supplemented with $50 \mathrm{~g} \cdot \mathrm{L}^{-1}$ maltose $(0.15 \mathrm{M}$; Tomaz et al., 2001). From that point forward, cultures were incubated at $28 \pm 2{ }^{\circ} \mathrm{C}$ with a 16 -h photoperiod $\left(70 \mu \mathrm{mol} \cdot \mathrm{m}^{-2} \cdot \mathrm{s}^{-1}\right)$. Somatic embryo formation occurred spontaneously from cultivated colonies 6 to 10 weeks after their initial plating on solid medium. Embryos larger than $3 \mathrm{~mm}$ were transferred directly to the fresh $0.15 \mathrm{~m}$ EME maltose medium. Smaller embryos were placed on the top of $0.22-\mu \mathrm{m}$ acetate plus membrane filters positioned over the $0.15 \mathrm{M}$ EME maltose medium to induce their enlargement. All somatic embryos were incubated on EME "1500" medium for enlargement and germination upon which their axes elongation was induced on $\mathrm{B}+$ and/or DBA3 shoot induction/multiplication medium (Grosser and Gmitter, 1990). Elongated shoots were transferred to Magenta vessels (GA-7) filled with RMAN rooting medium (Grosser and Gmitter, 1990) for root induction. Regenerated shoots of putative hybrids were micrografted onto trifoliate Carrizo citrange $(C$. sinensis $\times$ Poncirus trifoliata) rootstock seedlings to expedite their growth (Dutt et al., 2009).

Unless otherwise stated, all media for callus induction/ maintenance, suspension maintenance, and plant regeneration from protoplasts were adjusted to $\mathrm{pH} 5.8$ with $1 \mathrm{~N} \mathrm{NaOH}$ and autoclaved at $121{ }^{\circ} \mathrm{C}$ for $20 \mathrm{~min}$. All media and solutions for protoplast isolation, fusion, and culture were filter-sterilized (0.22 $\mu \mathrm{m}$ pore size).

Ploidy Determination. Somatic regenerants were screened by flow cytometry to determine their ploidy level while they were still growing in vitro. The relative amount of nuclear DNA content was measured in leaf samples of regenerated plants using a tabletop ploidy analyzer (Partec, Munster, Germany). A small piece of leaf $\left(\approx 0.2 \mathrm{~cm}^{2}\right)$ was chopped in the extraction buffer, passed through a nylon mesh sieve ( $45-\mu \mathrm{m}$ pore size), and stained with fluorescent dye [4',6-diamidino-2-phenylindole (DAPI)]. Both, the extraction buffer and DAPI were obtained from a high-resolution staining kit (Partec). The ploidy level of nuclei from each leaf sample was determined by peak position relative to those of the control diploid (2x) and tetraploid (4x) plants presented on the histogram produced by the ploidy analyzer.

EST-SSR MOLECULAR ANALYSIS. Selected somatic tetraploid plants were further tested with molecular markers using EST-SSR method to determine whether they were autoor allotetraploids. Genomic DNA of recovered tetraploid plants and trueto-type field-grown trees was isolated from 0.1 to $0.3 \mathrm{~g}$ leaf pieces
Fig. 1. Division of fused protoplasts and creation of colonies following polyethylene-glycol-mediated protoplast fusion (400×): (A) protoplasts obtained from fusion of protoplast isolated from nucellar callus (from 'W. Murcott' tangor) and leaf-derived protoplast (from 'Ponkan' mandarin); (B) the first cell division of fused protoplast; $(\mathbf{C})$ the second cell division of fused protoplast; (D) immature colony; and (E) mature colony. 
using GenElute Plant Genomic DNA Kit (Sigma-Aldrich, St. Louis, MO). Each sample was tested with 10 previously tested primers (CX6F04, CX6F17, CX6F18, CX6F21, CX6F30, CX5F57, CX0010, CX0035, CX2007, and CX2021) that were proven useful in distinguishing between closely related mandarins (Chen et al., 2006, 2008b). Isolated DNA samples were amplified by polymerase chain reaction (PCR) (C-1000; Bio Rad, Hercules, CA) and amplicons were resolved in a genetic analyzer (3130xl; Applied Biosystems, Foster City, CA), as described by Chen et al. (2006). Generated chromatographic files were further analyzed with GeneMarker (SoftGenetics, State College, PA) to score alleles for all the parents and regenerated somatic tetraploids into a table. Alleles in each regenerated tetraploid plant were compared with those in their donor parents to determine whether the plant is auto- or allotetraploid. An autotetraploid plant had alleles from only one donor parent. An allotetraploid had alleles combined from both donor parents.

When alleles in somatic tetraploids were not detected in the callus-line donor parent, additional EST-SSR analysis was performed on leaf DNAs of the source parent plants that were used to generate embryogenic callus lines from their ovule tissues, to determine the nucellar or zygotic origin of these ovule-derived tissues. Twenty-four callus lines for 'Murcott' and 18 for 'W. Murcott' tangor were compared.

Morphological evaluation. Fully developed leaves were collected from regenerated plants and their parents. They were examined and compared for morphological differences in leaf shape, size, and appearance of petioles.

\section{Results}

Optimization OF CUlture MEdium FOR INDUCTION OF EMBRYOGENIC CALLUS. Callus induction from nucellar layer of ovules was the lowest in all four cultivars when medium without kinetin was used (Fig. 2). Addition of kinetin to the medium at concentration of 5 and $10 \mathrm{mg} \cdot \mathrm{L}^{-1}$ produced high frequency of responding ovules without statistical differences between these two treatments for all tested cultivars except Ponkan. In the case of 'Ponkan', the addition of $10 \mathrm{mg} \cdot \mathrm{L}^{-1}$ kinetin to the medium produced statistically higher callus production when compared with two times lower concentration. Genotype also had an effect on callus induction (Fig. 2). When $5 \mathrm{mg} \cdot \mathrm{L}^{-1}$ kinetin was added to the medium, maximum frequency of responding ovules was recorded in 'W. Murcott' $(\approx 60 \%)$. On the same medium, callogenesis of 'Page' and 'Ponkan' on the level of $25 \%$ was significantly higher than in 'Murcott'. Even more variability in results was seen when callus formation for different cultivars was compared on medium supplemented with $10 \mathrm{mg} \cdot \mathrm{L}^{-1}$ kinetin. Approximately $18 \%$ of all cultured explants produced callus in 'Murcott', in comparison with $25 \%$ in 'Page' and $45 \%$ in 'Ponkan'. The highest frequency of responding explants $(57 \%)$ was observed in 'W. Murcott'.

Genotype affected embryogenesis far less than callogenic frequency. Based on statistical analysis by the Duncan test, the ability of isolated ovules to produce embryos was more dependent on the presence of kinetin in the medium than genotype. For all four tested cultivars, maximum frequency of responding ovules to produce nucellar embryos of $20 \%$ to $30 \%$ was observed when ovules were cultured on basal medium without the growth regulator (Fig. 3). On the medium supplemented with kinetin ( 5 and $10 \mathrm{mg} \cdot \mathrm{L}^{-1}$ ), embryogenesis was not higher than $10 \%$, but the percentage of responding ovules to produce embryos was significantly higher in 'Page' and 'Murcott' in comparison with the other two cultivars. The frequency of ovules producing somatic embryos on medium with $10 \mathrm{mg} \cdot \mathrm{L}^{-1}$ kinetin was the highest in 'Page', lower in 'Murcott', and almost not present in 'Ponkan' and 'W. Murcott'. The phases of production between the culture of mature cell colonies and regenerated plants are presented in Fig. 4.

OPTIMIZATION OF ENZYME

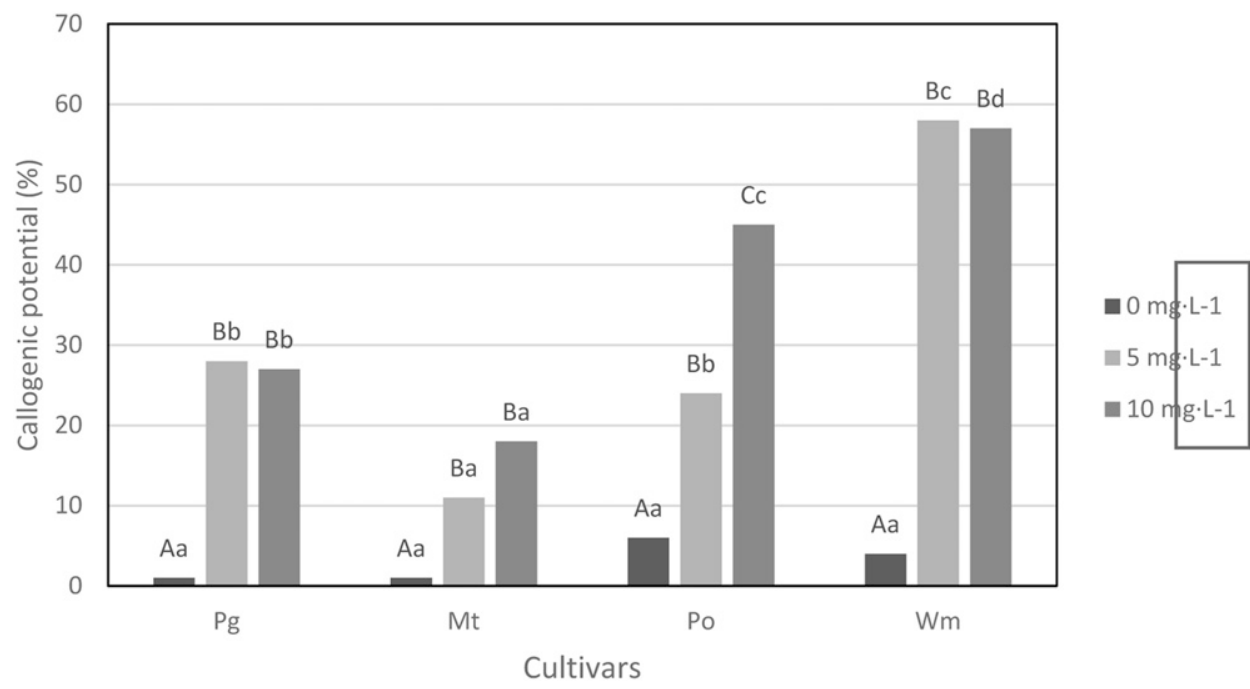

Fig. 2. The effect of three induction media on callusogenesis (calculated as $\%$ of ovules that responded to the media after 9 months of in vitro culture). The four citrus cultivars are Ponkan mandarin (Po), Page tangelo (Pg), Murcott tangor (Mt), and W. Murcott tangor (WM). Different letters above columns indicate that mean values are significantly different at $P<0.05$ according to Duncan's multiple range test. Capital letters $(\mathrm{A}, \mathrm{B}, \mathrm{C})$ refer to differences in callogenesis for each individual cultivar grown on three different induction media while small letters $(a, b, c)$ refer to differences in callogenesis among four different cultivars for each tested induction medium.
SOLUTION FOR THE PROTOPLAST ISOLATION FROM BOTH SOURCES: EMBRYOGENIC CELL SUSPENSION AND NONEMBRYOGENIC IN VITRO-GROWN LEAVES. Samples of established suspension cultures maintained in $\mathrm{H}+\mathrm{H}$ liquid medium and finely chopped segments of leaves from in vitrogrown plants were treated with three different formulations of enzyme mix for release and purification of protoplasts. On completion of subsequent steps in the protoplast isolation protocol, protoplasts were counted and the yields are presented in Table 1. Enzyme mix $\mathrm{C}$ was the most effective for isolation of protoplasts from both sources: cell suspension cultures and in vitro-grown leaves. For cultivars Willowleaf, Ponkan, and Murcott, enzyme mix $\mathrm{C}$ was almost two times more effective than the mix B. Treatments with both mixes $B$ and $C$ resulted in 


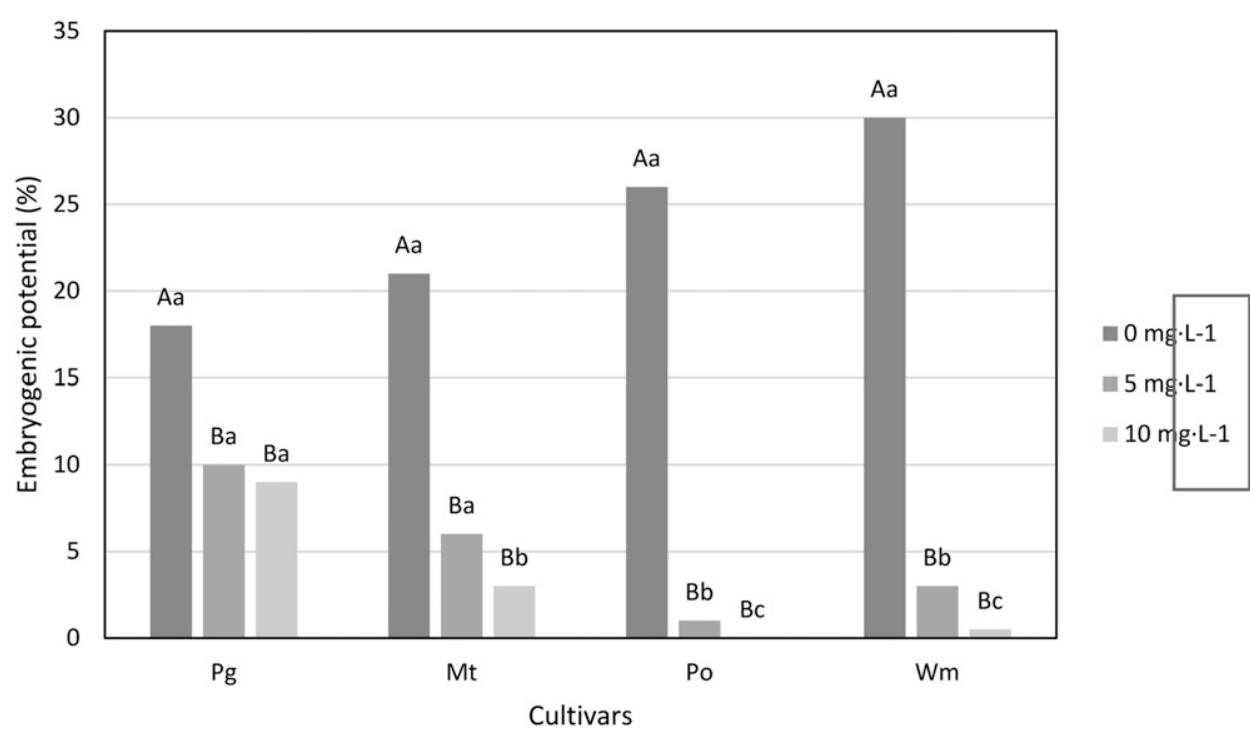

Fig. 3. The effect of three embryo induction media on embryogenesis (calculated as the percentage of ovules that responded to the media after 9 months of in vitro culture). The four citrus cultivars are Ponkan mandarin (Po), Page tangelo (Pg), Murcott (Mt), and W. Murcott (WM) tangor. Different letters above columns indicate that mean values are significantly different at $P<0.05$ according to Duncan's multiple range test. Capital letters (A, B, C) refer to differences in embryogenesis for each individual cultivar grown on three different induction media while small letters $(a, b, c)$ refer to differences in embryogenesis among four different cultivars for each tested induction medium.
$\mathrm{WM}+\mathrm{Sn}$ and $\mathrm{WM}+\mathrm{Ki}$ had the highest number of tetraploid plants produced when PEG-1500 was added to the protoplast fusion mix (Table 2).

For the six parental combinations where regenerated plantlets were produced, numbers varied from 86 for $\mathrm{WM}+\mathrm{Ki}$ to 1335 for $\mathrm{WM}+\mathrm{WL}$. A percentage of tetraploid plants in relation to total number of regenerated plants ranged between $1 \%$ and $3 \%$ for most of the combinations $(\mathrm{Mt}+\mathrm{WL}, \mathrm{WM}+\mathrm{Po}, \mathrm{WM}+\mathrm{WL}$, $\mathrm{WM}+\mathrm{Ki}$, and $\mathrm{WM}+\mathrm{Sn}$ ), whereas it was much higher for Po+MW (13\%, Table 2). Among those combinations that yielded tetraploid plants, for three of them $(\mathrm{Mt}+\mathrm{WL}$, $\mathrm{Po}+\mathrm{WM}$, and $\mathrm{WM}+\mathrm{Po}$ ) there was a positive effect of addition of highest MM PEG to protoplast fusion mix on the number of produced tetraploid plants. The addition of PEG-6000 facilitated production of tetraploid plants for only two combinations $(\mathrm{Mt}+\mathrm{WL}$ and $\mathrm{WM}+\mathrm{WL})$, whereas PEG-8000 aided this prosimilar protoplast yield for 'W. Murcott'. Enzyme mix B was more effective only in isolation of protoplasts from 'Page'. The efficacy of enzyme mix A was extremely low and in some cases treatment with this formulation was toxic (Table 1). On treatment with enzyme mix A, protoplasts busted and their content spilled into the nutrient medium. Highest protoplast yield across all treatments was achieved with the use of enzyme mix $C$ and cell suspension samples from the 'Willowleaf' [13.8 million (Table 1)]. Based on these results, enzyme mix $C$ was used in subsequent experiments. Similar results were obtained when leaves were used as a source material for protoplast isolation (data not shown).

The efFect of PEG treatment on PRotoplast fusion. Protoplasts isolated from embryogenic cell suspension cultures of 'Murcott', 'Page', 'Ponkan', and 'W. Murcott' were used in combination with protoplasts obtained from leaves of in vitrogrown plants of 'Willowleaf', 'Snack', 'Ponkan', 'Kinnow', 'Osceola', and 'W. Murcott' for the purpose of production of somatic hybrids through protoplast fusion. Appropriate mixes of embryogenic and nonembryogenic protoplasts were treated with the solutions of $40 \%(\mathrm{w} / \mathrm{v})$ PEG that facilitate protoplast fusion. PEG of three different MMs (1500, 6000, and 8000) was used to make these solutions (Table 2). All regenerated plants were subjected to flow cytometry analysis and EST-SSR analysis for identification of auto- and allotetraploids.

Raising the MM of applied PEG had no effect on four combinations of protoplasts $(\mathrm{P}+\mathrm{Sck}, \mathrm{P}+\mathrm{WL}, \mathrm{P}+\mathrm{WM}$, and $\mathrm{Po}+\mathrm{Osc}$ ), as no plants were regenerated (Table 2). In two other combinations ( $\mathrm{Mt}+\mathrm{Osc}$ and $\mathrm{Po}+\mathrm{WL}$ ), some plants were regenerated ( 9 and 47 , respectively), but none of them were polyploid based on flow cytometry testing. For these two combinations, as well as four other combinations, where tetraploid plants were produced $(\mathrm{Mt}+\mathrm{WL}, \mathrm{Po}+\mathrm{WM}, \mathrm{WM}+\mathrm{Po}$, and $\mathrm{WM}+\mathrm{WL})$, the addition of highest MM PEG to protoplast fusion mix resulted in the highest number of regenerated plants. Combinations cess for six parental combinations. Based on these results, PEG8000 was used in subsequent experiments for production of tetraploid plants through protoplast fusion.

EST-SSR ANALYSIS OF TETRAPLOID PLANTS AND CALLI DERIVED From 'Murcott' AND 'W. Murcott' ovules. According to EST-SSR marker analysis, 46 regenerants were identified as autotetraploids that had the same SSR alleles as one of their parents; 18 were allotetraploids that had EST-SSR markers with alleles combined from both parents; and one was undefined as either auto- or allo- tetraploid due to the complexity of allele profiles between the tetraploid and their presumed parents (Table 3). All the tretraploids were grouped into 14 somatic hybridization combinations. The number of confirmative markers for all the 14 combinations ranged from three to seven. Combination 1 to 9 produced autotetraploids from either the callus parents (Combination 1-6 and 8-9) or the leaf parent ('Willowleaf' in Combination 7). Combination 11 to 14 apparently produced allotetraploids that had alleles combined from both the callus and leaf parents in some EST-SSR markers (e.g., CX6F17 and CX2007), although contradicting allele patterns existed in other markers (e.g., CX6F30 and CX0035) (Table 3). For example, at CX6F30, all the hybrids from Combination 12 to 14 did not have allele 93 that was detected in the leaf parent 'W. Murcott'. Similarly, at CX3005, all the hybrids from Combination 12 to 14 did not have allele 183 that was detected in the leaf parent 'W. Murcott'. The only possible explanation was that some embryos within the seeds used to produce the seedling leaf parents were also of zygotic origin. They were different from the mother tree that produced the seeds and were used for DNA extraction and genotyping, similar to some validated zygotic callus lines below. Regrettably, these seedlings (leaf parents) were no longer available for marker analysis to compare with their mother trees and confirm our explanation, as we did on these callus lines. The only "undefined" tetraploid from Combination 10 represented one extreme case with 


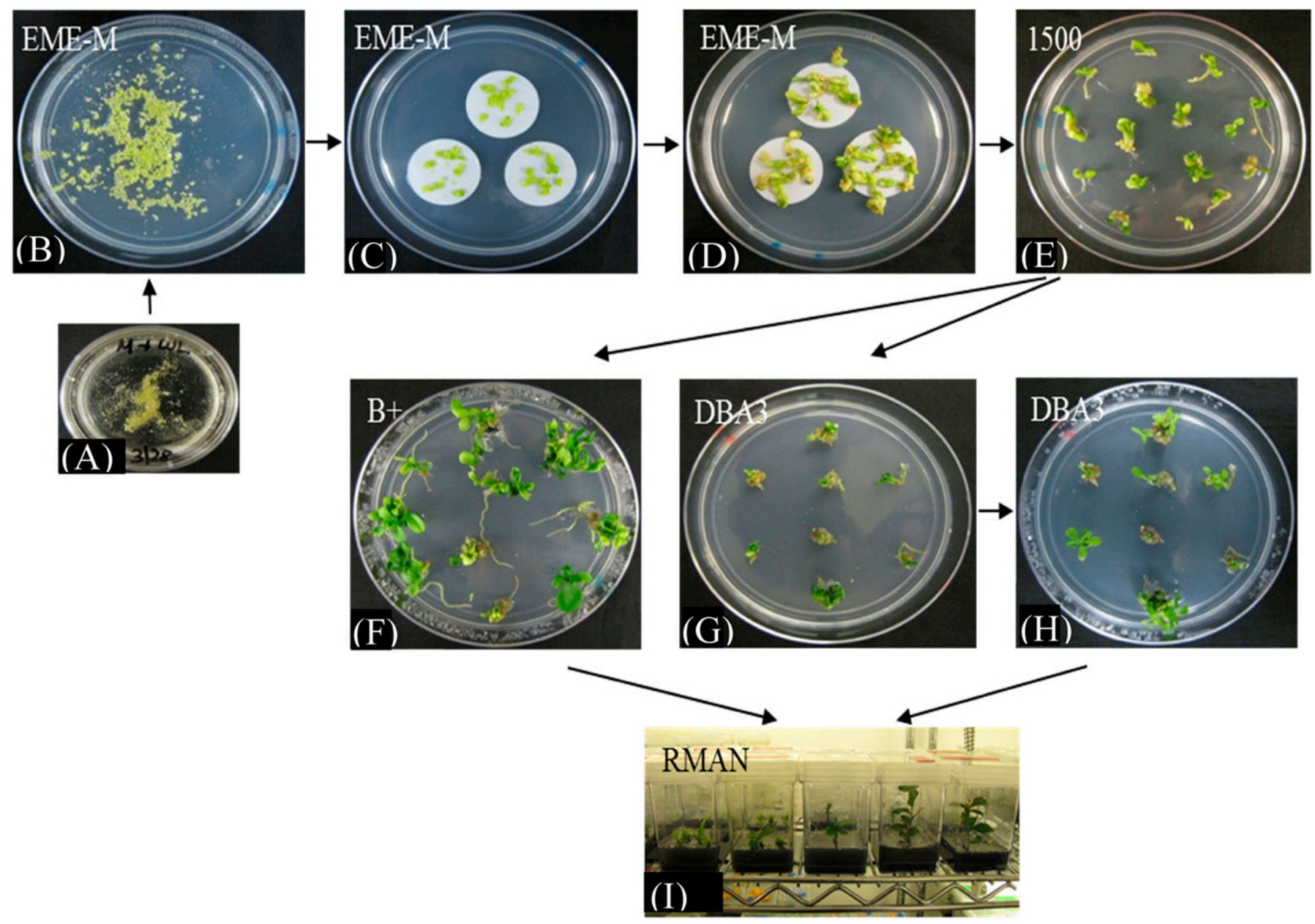

Fig. 4. Phases between culture of mature cell colonies and regenerated plants. Parental material came from 'W. Murcott' tangor and 'Ponkan' mandarin. (A) Mature colonies in the liquid media; (B) generation of somatic embryos upon transfer of colonies to $0.15 \mathrm{~m}$ EME-malt solid embryo induction medium (Grosser et al., 2010b); (C, D) growth of somatic embryos on the surface of aceto-cellulose filter papers placed on top of solid medium; (E) maturation of somatic embryos on EME 1500 embryo enlargement medium (Grosser et al., 2010b); (F) elongation growth of embryos on B+ embryo germination medium (Grosser and Gmitter, 1990); (G, H) induction of organogenesis in undeveloped embryos on DBA3 shoot induction/multiplication medium (Grosser and Gmitter, 1990); and (I) growth and rooting of plants on RMAN rooting medium (Grosser and Gmitter, 1990) in Magenta vessels (GA-7; Magenta, Lockport, IL).

Table 1. Total number of isolated protoplasts following the treatment with different formulations of enzyme mix. The source material for protoplast isolation was cell suspension. Results are presented as means from three repetitions.

\begin{tabular}{lccr}
\hline & \multicolumn{3}{c}{ Enzyme mix } \\
\cline { 2 - 4 } Cultivar & \multicolumn{1}{c}{$\mathrm{A}$} & $\mathrm{B}$ & $\mathrm{C}$ \\
\cline { 2 - 4 } Willowleaf mandarin & \multicolumn{2}{c}{ Isolated protoplasts $[$ mean \pm sE $($ million/g fresh wt)] } \\
W. Murcott tangor & $0.5 \pm 0.7$ & $7.1 \pm 1.6$ & $13.8 \pm 3.9$ \\
Ponkan mandarin & $0.1 \pm 0.1$ & $5.0 \pm 1.1$ & $5.6 \pm 0.9$ \\
Page tangelo & $0.3 \pm 0.2$ & $3.0 \pm 1.7$ & $6.8 \pm 3.6$ \\
Murcott tangor & $0.3 \pm 0.1$ & $9.6 \pm 1.8$ & $5.6 \pm 3.7$ \\
\hline
\end{tabular}

WM callus 2-4 were from selfing and WM callus 5 from outcrossing, according to their allele profiles (Table 4).

EVALUATION OF MORPHOLOGY OF LEAVES FROM SOMATIC REGENERANTS. Leaves of some allotetraploids did not look like leaves of their parents (Fig. 5). Allotetraploid somatic hybrid between 'Ponkan' and 'W. Murcott' [Fig. 5E (genotype no. 12 from Table 3)] has leaves with morphological features that are inuninterpretable allele patterns between the tetraploid and its presumed parents (Table 3 ).

EST-SSR analysis of 24 ovule-derived calli from 'Murcott' has shown that all had profiles identical to the mother plant (data not shown). However, among 18 calli derived from 'W. Murcott' ovules, only four of WM callus 1 had EST-SSR profile identical to that of the mother plant, suggesting they were of nucellar origin. All the others were of zygotic origin; likely between those of leaves of its parents (Fig. 5A and B). The leaves from 'W. Murcott' autotetraploid plants produced from two different attempted fusions of 'W. Murcott' with 'Ponkan' and 'Willowleaf' showed similarity mostly to leaves of 'W. Murcott' (Fig. 5B, F, and H). Even stronger similarity was found between the leaves of autotetraploid 'Willowleaf' mandarin and one of its parents (Fig. 5C and G), which is not surprising as they have an identical allelic profile according to EST-SSR analysis 
Table 2. The effect of polyethylene glycol (PEG) of different molecular mass $(1500,6000$, and 8000$)$ on fusion between embryogenic and nonembryogenic protoplasts for different parental combinations. Number of regenerated plants refers to all plants before their level of ploidy was checked. Percentage of tetraploid plants out of all regenerated plants is presented in parentheses. The data are cumulative values from three to five repeated experiments.

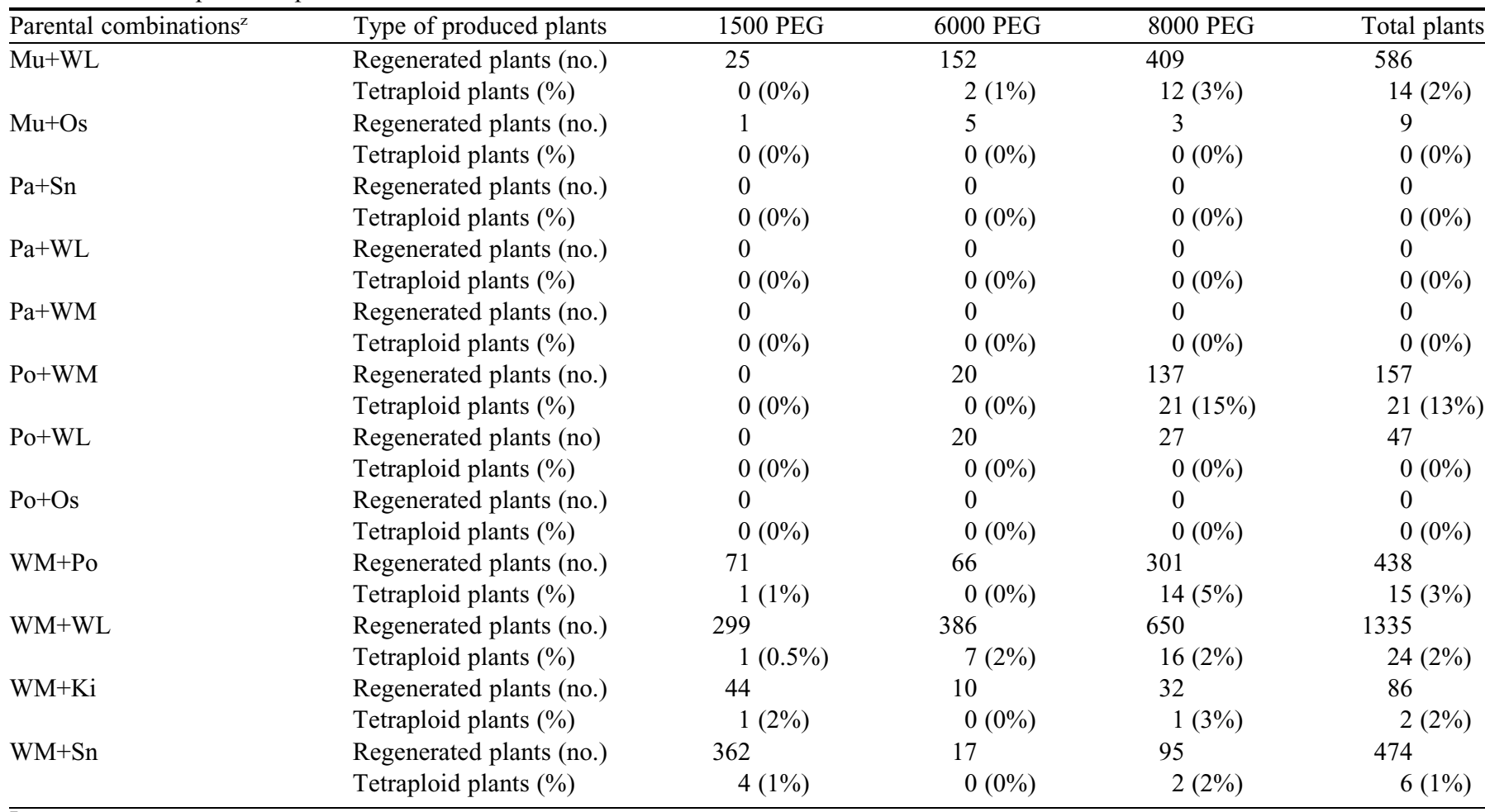

${ }^{\mathrm{z}}$ Letters before and after plus sign $(+)$ designate cultivars and hybrids from which embryogenic and nonembryogenic protoplasts were isolated, respectively: $\mathrm{Mu}=$ Murcott tangor, $\mathrm{Pa}=$ Page tangelo, $\mathrm{Po}=$ Ponkan mandarin, $\mathrm{WM}=\mathrm{W}$. Murcott tangor, $\mathrm{WL}=\mathrm{Willowleaf}$ mandarin, Os $=$ Osceola tangelo, $\mathrm{Sn}=$ Snack tangor, $\mathrm{Ki}=$ Kinnow mandarin.

(Table 3). The leaves of 'Murcott' autotetraploids generated in the attempted fusion of 'Murcott' and 'Willowleaf' were mostly similar to leaves of the 'Murcott' parent (Fig. 5C and D).

\section{Discussion}

Because of the problems related to the reproductive nature of citrus such as sexual incompatibility, nucellar polyembryony (apomixis), the sterility of pollen and egg cells, heterozygosity, and long juvenile phase, most cultivars of scions and rootstocks grown presently were not generated as a result of breeding but were the product of natural mutations (Grosser and Gmitter, 1990). The practical value of somatic hybridization is that it allows the transfer of genes from the wild, sexually incompatible relatives to the commercially important citrus cultivars and increases genetic variability through combination of nuclear, mitochondrial, and chloroplast genomes into new cultivars (Dudits et al., 1980; Grosser et al., 1996). Products of somatic hybridization can be symmetrical auto- and allotetraploid somatic hybrids, asymmetrical somatic hybrids and somatic cybrids (Grosser et al., 2010a). Tetraploid somatic hybrids can have only certain traits, like fruit size or sugar content, improved while other traits remain unchanged. Such hybrids will not be used as new cultivars but can still be used as parents in interploid sexual hybridization with the ultimate goal of obtaining seedless triploid hybrids (Grosser and Gmitter, 2011). In this project, popular mandarin cultivars with superior features were used as sources of both embryogenic and nonembryogenic material for protoplast fusion. Through modifi- cations of the existing previously used PEG-mediated method for protoplast fusion, we produced some new tetraploids that could potentially be reciprocally crossed to diploids as a way of creating triploids, if any of the tetraploids are sufficiently monoembryonic. Due to specific demands of consumers, seedlessness in fruit is usually the primary goal of mandarin improvement. However, there are other traits related to the quality of the fruit that can be transferred to triploid offspring by interploid hybridization, including disease resistance, tolerance to extreme environmental conditions, easy peeling, dark orange-colored rind and flesh, good taste, extension of the fruitbearing season, increase in the ability to withstand transport, and longer shelf life.

Successful regeneration of somatic hybrids after protoplast fusion can be achieved only if the protoplasts from at least one parent have embryogenic capacity (Grosser and Gmitter, 1990). For somatic hybridization in citrus, protoplasts from totipotent embryogenic callus/cell suspensions are usually fused with non-totipotent protoplasts from leaves. Production of embryogenic cell suspension from ovules of four mandarin cultivars: Murcott, Page, Ponkan, and W. Murcott, included a step of callus induction that was promoted by the use of media with different concentrations of kinetin. Without kinetin, callogenesis was lower than 5\% (Fig. 2). On the contrary, the presence of kinetin greatly inhibited embryogenesis from calli (Fig. 3). The concentration of $5 \mathrm{mg} \cdot \mathrm{L}^{-1}$ of kinetin was found to be sufficient to induce production of callus but also to keep it in an undifferentiated state without producing multiple embryos (Figs. 4 and 5). Starrantino and Caponnetto (1990) also showed 


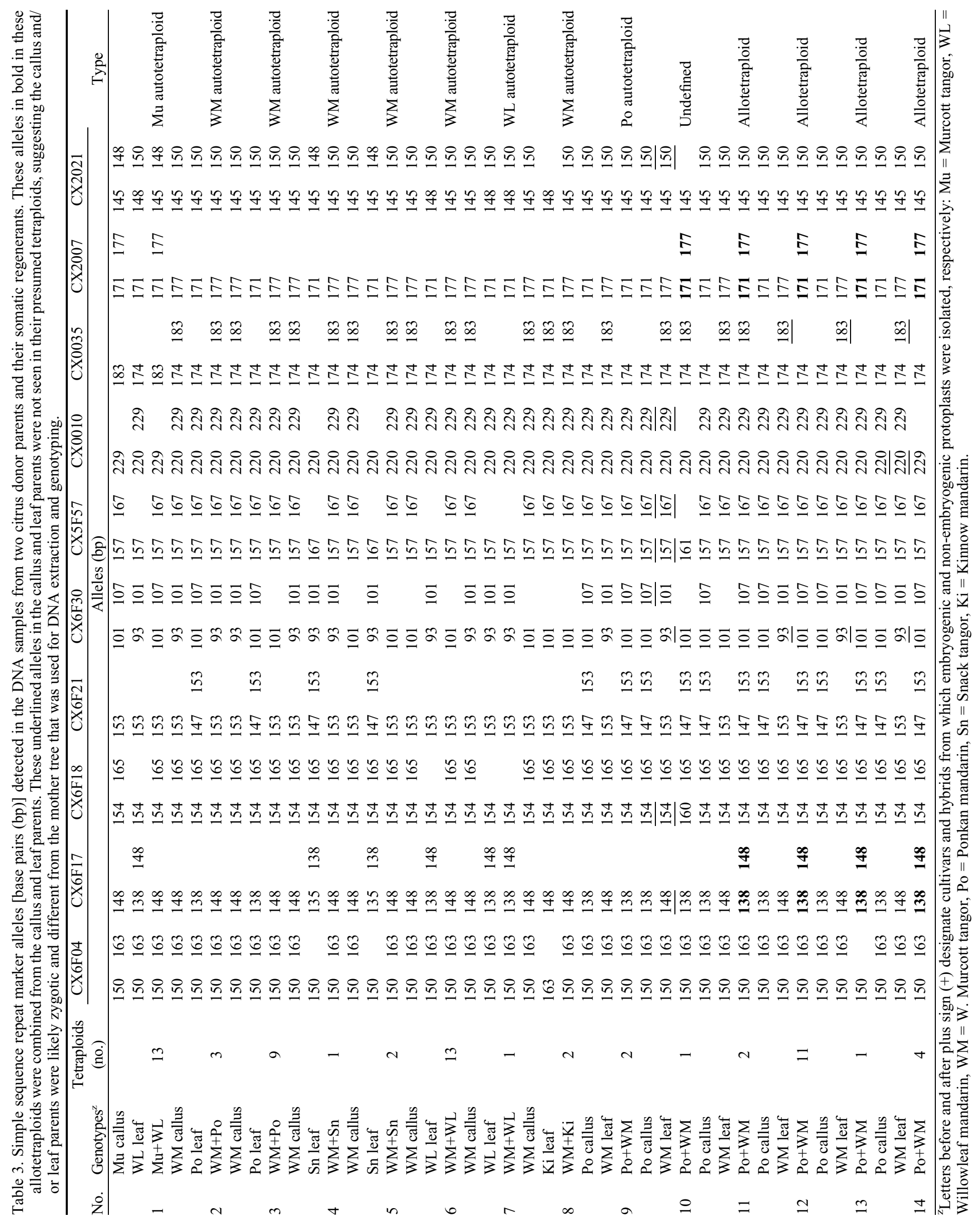


Table 4. Simple sequence repeat marker alleles [base pairs (bp)] detected in the DNA samples from 'W. Murcott' tangor (WM) leaf and their five callus lines. The callus lines with marker alleles in bold were confirmed to have zygotic origin. Alleles from markers CX6F18, CX6F21, CX2007, CX0010, and CX2021, were excluded from this table because each marker detected the same alleles in all the samples and did not contribute any new information.

\begin{tabular}{|c|c|c|c|c|c|c|c|c|c|c|c|c|}
\hline \multirow[b]{2}{*}{ DNA sources } & \multirow{2}{*}{$\begin{array}{c}\text { Tested } \\
\text { (no.) }\end{array}$} & \multicolumn{2}{|c|}{ CX6F04 } & \multicolumn{2}{|c|}{ CX6F17 } & \multirow{2}{*}{\multicolumn{2}{|c|}{$\begin{array}{c}\text { CX6F30 } \\
\text { Alleles (bp) }\end{array}$}} & \multicolumn{2}{|c|}{ CX5F57 } & \multicolumn{2}{|c|}{ CX0035 } & \multirow[b]{2}{*}{ Origin } \\
\hline & & & & & & & & & & & & \\
\hline WM leaf & 1 & 150 & 163 & 148 & & 93 & 101 & 157 & 167 & 174 & 183 & - \\
\hline WM callus 1 & 4 & 150 & 163 & 148 & & 93 & 101 & 157 & 167 & 174 & 183 & Nucellar \\
\hline WM callus 2 & 1 & 163 & & 148 & & 93 & 101 & 157 & 167 & 174 & 183 & otic \\
\hline WM callus 3 & 1 & 163 & & 148 & & 101 & & 157 & 167 & 174 & 183 & Zygotic \\
\hline WM & 11 & 150 & 163 & 148 & & 101 & & 157 & 167 & 174 & 183 & Zygotic \\
\hline WM callus 5 & 1 & 150 & 163 & 138 & 148 & 93 & 101 & 157 & & 174 & & Zygotic \\
\hline
\end{tabular}
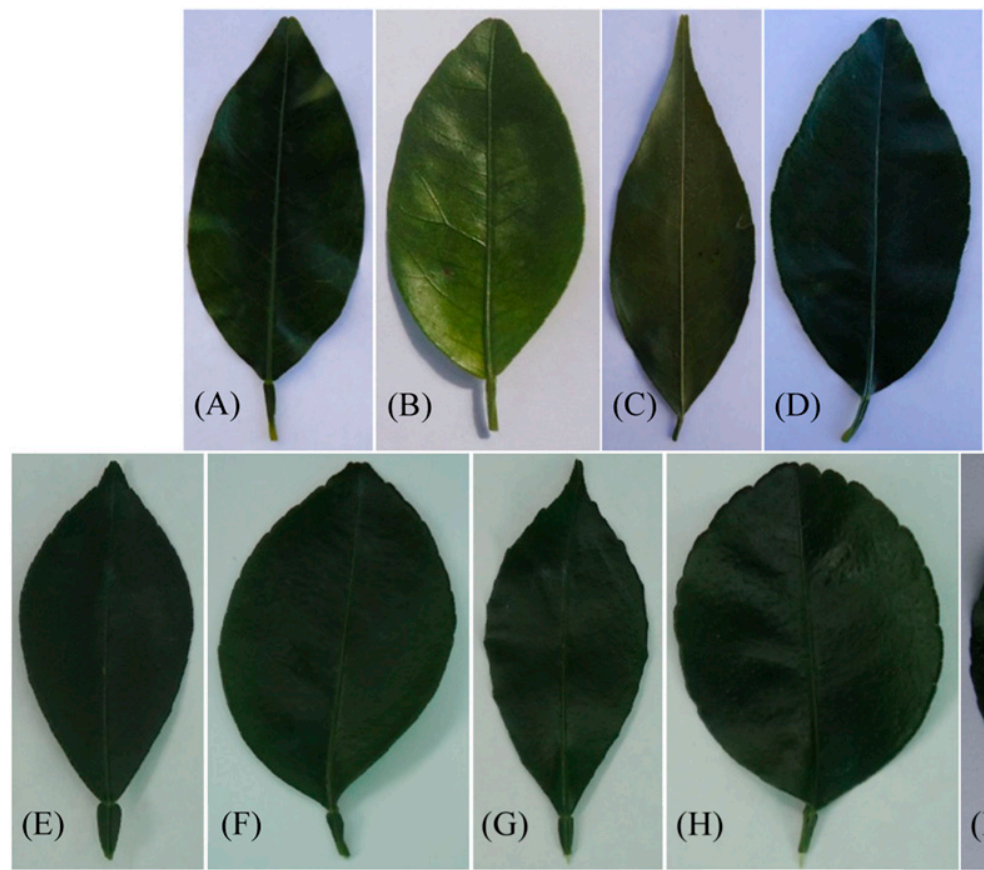

Fig. 5. Leaf morphology of parents (top row) and six somatic hybrids (bottom row). Top: (A) 'Ponkan' mandarin, (B) 'W. Murcott' tangor, (C) 'Willowleaf' mandarin, (D) 'Murcott' tangor. Bottom: (E) 'Ponkan' + 'W. Murcott' allotetraploid, (F) 'W. Murcott' autotetraploid that was produced in 'W. Murcott' + 'Ponkan' fusion, (G) 'Willowleaf' autotetraploid that was produced in 'W. Murcott' + 'Willowleaf' fusion, (H) 'W. Murcott' autotetraploid that was produced in 'W. Murcott' + 'Willowleaf' fusion, and (I) 'Murcott' autotetraploid that was produced in 'Murcott' + 'Willowleaf' fusion.

that the nutrient medium for the induction of embryogenic callus from nucellar tissue from ovules of five different sweet orange cultivars is more effective when it contains cytokinins. The effect of the addition of two cytokinins-kinetin and 6-benzyl-aminopurine (BAP) to MT medium at four different concentrations $\left(0,2.5,5.0\right.$, and $\left.10.0 \mathrm{mg} \cdot \mathrm{L}^{-1}\right)$ was examined. From these experiments, it was concluded that the highest callogenic potential was achieved when the medium was supplemented with BAP at a concentration of $10.0 \mathrm{mg} \cdot \mathrm{L}^{-1}$, or when both BAP and kinetin were present in the medium at a concentration of 5 to $10 \mathrm{mg} \cdot \mathrm{L}^{-1}$. In the work done with oranges, mandarins, grapefruit, tangors, and tangelos (Grosser et al., 2000), three types of media were successfully used for induction of $\approx 50$ different embryogenic callus lines from immature ovules: 0.146 EME without any hormones; 0.146

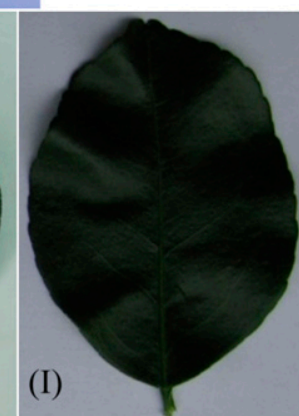

EME supplemented with $44 \mu \mathrm{M} 6-$ BAP and $0.04 \mu \mathrm{M} 2,4-\mathrm{D}$; and $\mathrm{H}+\mathrm{H}$.

To produce high yields of goodquality protoplasts from mandarin cell suspensions, the capability of different formulations of enzyme solution to disrupt plant tissue into the individual cells and digest the cell walls of individual cells was tested. In the enzymatic solutions that were used in the procedures for the fusion of plant cells, there were various combinations of enzymes that break down the main constituents of the cell wall: pectin, cellulose, and hemicellulose (xylan) (Evans and Bravo, 1983). The presence of even the smallest remnants of the cell wall on the plasmalemma can interfere with the creation of close contact between the cell membrane of protoplasts that are fused, and arrest that process. The total number of isolated protoplasts, expressed in millions per gram of fresh weight, for five mandarin cultivars showed that enzyme formulations $\mathrm{B}$ and $\mathrm{C}$ were more efficient than formulation A (Table 1). Furthermore, enzyme formulation A in some cases had a toxic effect. Because formulation A was the only one that contained pectolyase, the negative effect was most probably the result of the activity of this enzyme. For three of five cultivars tested, formulation $\mathrm{C}$ was almost two times more efficient than formulation B (Table 1). Contrary to the results of our experiments, pectolyase has been successfully used for the isolation of protoplasts of different types of citrus and other fruit and vegetable crops combined with cellulase and macerase and many other enzymes (Mendes-da-Gloria et al., 2000; Prakash and Foxe, 1984; Xu et al., 2007). Considering that our media recipes and protocols do not differ from those previously reported, there is a chance that the manufacturer of the enzyme has changed something in the composition or source of the product.

PEG-based method for protoplast fusion in citrus is favored because it is simple, effective, and inexpensive. Once the optimal molecular weight and the concentration of PEG for each cultivar is defined and applied, a negative effect on the viability of the protoplasts is reduced. PEG is a polymer and has a large molecular weight in the range of up to 20,000. However, only in a certain concentration ( $25 \%$ to $33 \%)$ and the specific molecular weight (1300-7500) can it lead to a successful agglutination of cells without making them burst (Constabel, 1984). The effect of $40 \%$ solution of PEG of three molecular weights $(1500,6000$, and 8000$)$ was tested on fusion of 
protoplasts in 12 parental combinations (Table 2). For those parental combinations that produced somatic hybrids, the increase in molecular weight of PEG was beneficial, with 8000 being the most effective (Table 2). Different molecular weights of PEG were reported to be successful in inducing protoplast fusion in different plant species. The PEG $1500 \mathrm{MM}$ was found to be the most efficient in protoplast fusion of 'Hamlin' sweet orange + Atalantia ceylanica combination (Louzada et al., 1993). For protoplast fusion of 'Hamlin' sweet orange with the other sexually incompatible relative Severinia buxifolia and 'Thompson' grapefruit with 'Murcott' tangor, 8000 MM of PEG produced best results (Grosser et al., 1992b). The production of somatic hybrids between 'Satsuma' mandarin and 'Navel' sweet orange worked best when PEG $6000 \mathrm{MM}$ (An et al., 2008) was used. All of these reports failed to report if different molecular weights of PEG had the effect on production of heterocaryon colonies or the number of somatic hybrids.

Successful mandarin plant regeneration was obtained in 8 of the 12 combinations of the parents that were used in fusion (Table 2). An interesting question here is whether applied chemical agents promoting protoplast production had a negative effect on protoplast fusion and somatic embryogenesis and, if so, why only one-third of parental combinations were affected.

Selection of somatic hybrids resulting from protoplast fusion is the most important phase in the production of new lines and/ or cultivars (Chen et al., 2008a; Guo et al., 2004). All mandarin plants that were candidates to be somatic hybrids were initially tested by flow cytometry (Fig. 6). Although this method provides information about ploidy level in produced plants, it cannot distinguish between auto- and allotetraploid individuals. EST-SSR molecular analysis uses codominant genetic markers that allow separation of homozygous and heterozygous loci in plants (Chen et al., 2008a; Fu et al., 2004; Guo et al., 2004;
Scarano et al., 2002). This method uses widespread existence of SSR sequences in both coding regions of genes as well as their introns (Chen et al., 2006; Scarano et al., 2002). Results of ESTSSR analyses of 65 tetraploid regenerants are presented in Table 3. Approximately $70 \%$ of produced plants (46) were found to be autotetraploids (genotypes 1-9). Another 18 plants $(\approx 28 \%)$ were determined to be allotetraploids and were grouped into genotypes 11 to 14 . For the plant with the genotype 10, results from the EST-SSR analysis were not conclusive and suggest that this plant might be a fusion product between something other than the two putative parental lines. When using protoplast fusion, production of both allo- and autotetraploid plants is common. Grosser et al. (1992a) reported production of autotetraploid plants of 'Hamlin' and 'Succari' sweet oranges in addition to 'Hamlin' sweet orange + 'Dancy' and 'Succari' sweet orange + 'Nova' tangelo ('Clementine' mandarin $\times$ 'Orlando' tangelo) allotetraploids. Similarly, in electrofusion between cells from embryogenic callus of 'Page' tangelo and mesophyll protoplast from rough lemon (Citrus jambhiri), many autotetraploid plants of 'Page' tangelo were obtained together with other allotetraploid hybrids (Guo et al., 2006).

Among allotetraploid mandarin plants, there were many that did not have allelic profiles identical to the sum of profiles of both parents (Table 3). Such a phenomenon was also reported when somatic hybrids were produced from various mandarin and pummelo parents (Chen et al., 2008a). Although all fusion products were allotetraploids, in 5 of 19 groups, the allelic profile of hybrids was not identical to allelic profile of mother 'Page' tangelo plants. Similar results were obtained in this project (Table 3); of 18 allotetraploid plants, none of them had an allelic profile that was identical to the sum of alleles present in genomes of both parents. Although these plants had the same parents, their allelic profiles showed great variability in relation to parental profiles; and for that reason, these plants

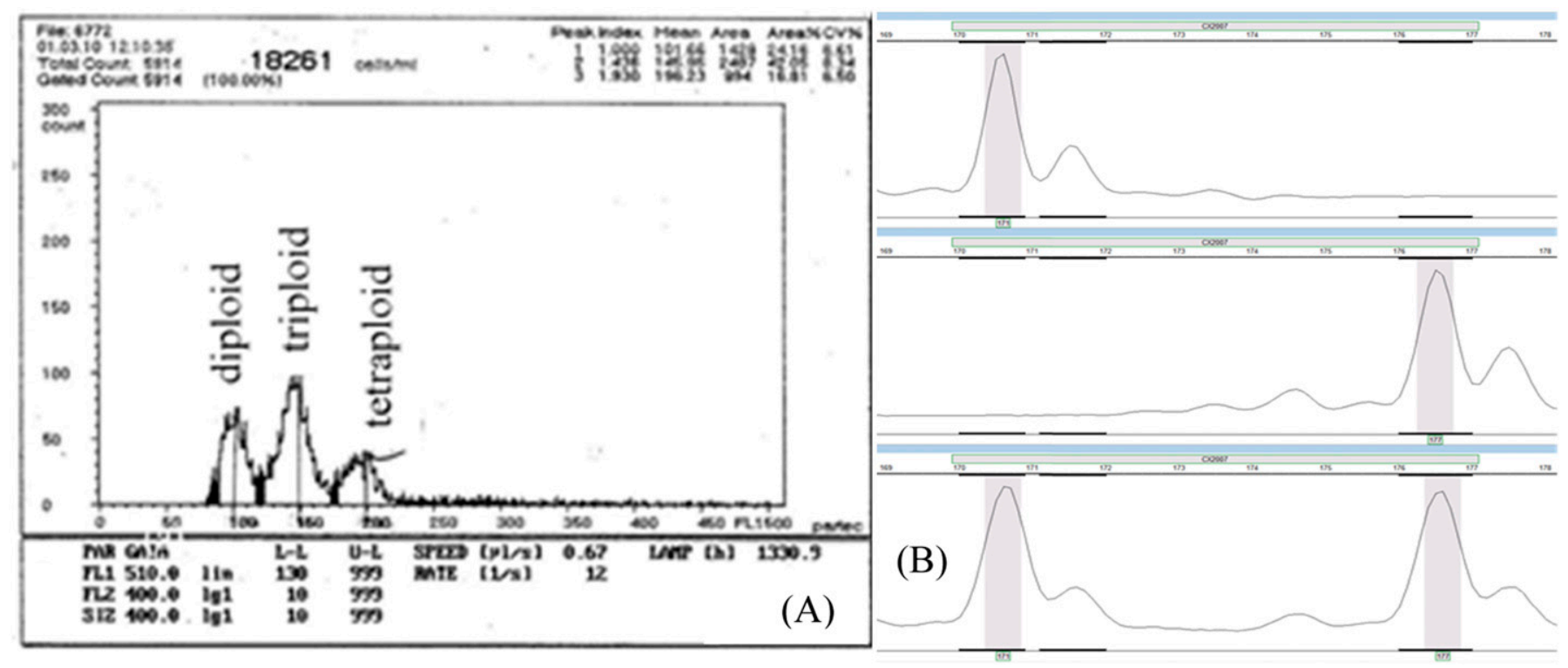

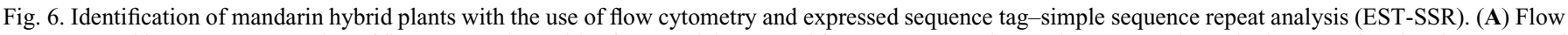
cytometry-histogram presentation of fluorescence intensities from nuclei extracted from regenerant plants. Fluorescence intensity is proportional to the amount of DNA in the nuclei. Each peak in the histogram represents the group of cells with the same ploidy level: 2x, 3x, or 4x. (B) Representative chromatograms of polymerase chain reaction products (primer CX2007) produced in EST-SSR analyses. Uppermost graph shows the homozygous allele [171 base pairs (bp)] in 'Ponkan' mandarin; middle graph shows the homozygous allele (177 bp) in 'W. Murcott' tangor; and the lowest graph shows the combined two alleles (171 and $177 \mathrm{bp}$ ) in their somatic allotetraploid. 
were classified into four different genotype groups (11-14). Regardless of type of ploidy in the progeny, the parental combination Po+WM produced the highest variability among plants belonging to six different genotypes (Table 3 ). The plant with complicated allelic profile that was assigned to its own genotype group was also a product of $\mathrm{Po}+\mathrm{WM}$ hybridization. Within the group of autotetraploid hybrids, only 20 of them had identical allelic profiles to profiles of their parents and the remaining 26 did not.

The fact that high percentage of produced somatic regenerants did not have an allelic profile identical to either the sum of the allelic profiles of parent plants, or to the allelic profile of single parent (Table 3 ) suggests that the initial material for the fusion was not identical ("true to type") to the parent plants. The variability detected in all $18 \mathrm{Po}+\mathrm{WM}$ allotetraploid plants came from the segment of allelic profile belonging to ' $\mathrm{W}$. Murcott' leaf parents [at various loci, one to three alleles were missing (Table 3)]. The presence of all other alleles from both leaf and embryogenic parental profiles in genomes of these hybrids suggests that some of the in vitro 'W. Murcott' stock plants used as a source of mesophyll protoplasts in fusion experiments must have been of zygotic origin (coming from cross-pollination and not from selfing). This was not expected, although it is not very surprising. It is known that citrus nucellar polyembryony exists as a form of asexual propagation and often occurs in the seed simultaneously and independently of the process of pollination and fertilization. As a result, one seed can contain a zygotic embryo and a large number of asexual (nucellar) embryos. Although nucellar embryos are "true-totype" to the seed parents, zygotic embryos are so-called "offtype" and derived from selfing or outcrossing segregation (Soost and Roose, 1996). This disagreement between SSR profiles of somatic regenerants and seed donor plants suggests zygotic origin of presumed nucellar callus. Such phenomenon was previously recorded for protoplast fusion that involved 'Page' and 'Satsuma' mandarins as the mother plants (Chen et al., 2008a; Grosser et al., 2010b).

EST-SSR analysis was used to determine whether some of the ovule-derived calli had a zygotic origin. When allelic profiles of calli obtained from individual 'Murcott' and 'W. Murcott' ovules were compared with allelic profiles of their donor plants, it was found that genotypes of all 24 callus lines from 'Murcott' were identical to their seed donor plant (data not shown). However, of 18 tested callus lines from 'W. Murcott', 14 of them exhibited variation in allelic profiles in relation to the seed donor plant. This is an indication of zygotic origin of most lines of embryogenic callus from ' $W$. Murcott' that were used in the somatic hybridization experiments (Table 4).

Morphological analysis of somatic hybrids is an important part of overall evaluation of somatic hybrids (Grosser and Gmitter, 1990). Observations of leaves from 18 allotetraploids produced from Po+WM fusion [genotypes 11-14 (Table 3)] showed that they have intermediary morphology compared with the leaves of their parental lines (Fig. 5A, D, and E). Intermediary vegetative morphology of allotetraploid plants in relation to their parents was previously reported for various types of citrus (Grosser et al., 1992a; Tusa et al., 1992). Those autotetraploid plants that have a duplicated genome of one parent from protoplast fusion [genotypes 1-9 (Table 3)] (Fig. $5 \mathrm{~F}$ and I) are expected to have leaf morphology similar to only one parent (Fig. 5B and D). These expected results were obtained for 37 plants [genotypes 1, 2, 4-9 (Table 3)], whereas nine 'W. Murcott' plants resulting from 'W. Murcott' + 'Ponkan' protoplast fusion [genotype 3 (Table 3, Fig. 5)] exhibited leaf morphology somewhat different from that of the embryogenic parent (Fig. 5). The leaves of these plants had poorly expressed petioles that are otherwise generally not found on the leaves of their parent, 'W. Murcott' tangor. This is most probably a consequence of the zygotic origin of protoplasts obtained from the 'W. Murcott' calli (Table 4).

Even though genomes of allotetraploid plants obtained in this study do not represent the sum of the genomes of their parent plants, they still may have value for the process of mandarin breeding by further increasing the genetic variability of lines that can be used as parents in interploid sexual hybridization. If, on the contrary, the goal of the project is to produce only the somatic hybrids with desired traits coming from selected parental lines, our results from EST-SSR analyses deserve careful consideration. Our recommendation is to properly authenticate whether both callus and leaf parents are "true to type" before somatic hybridization to ensure

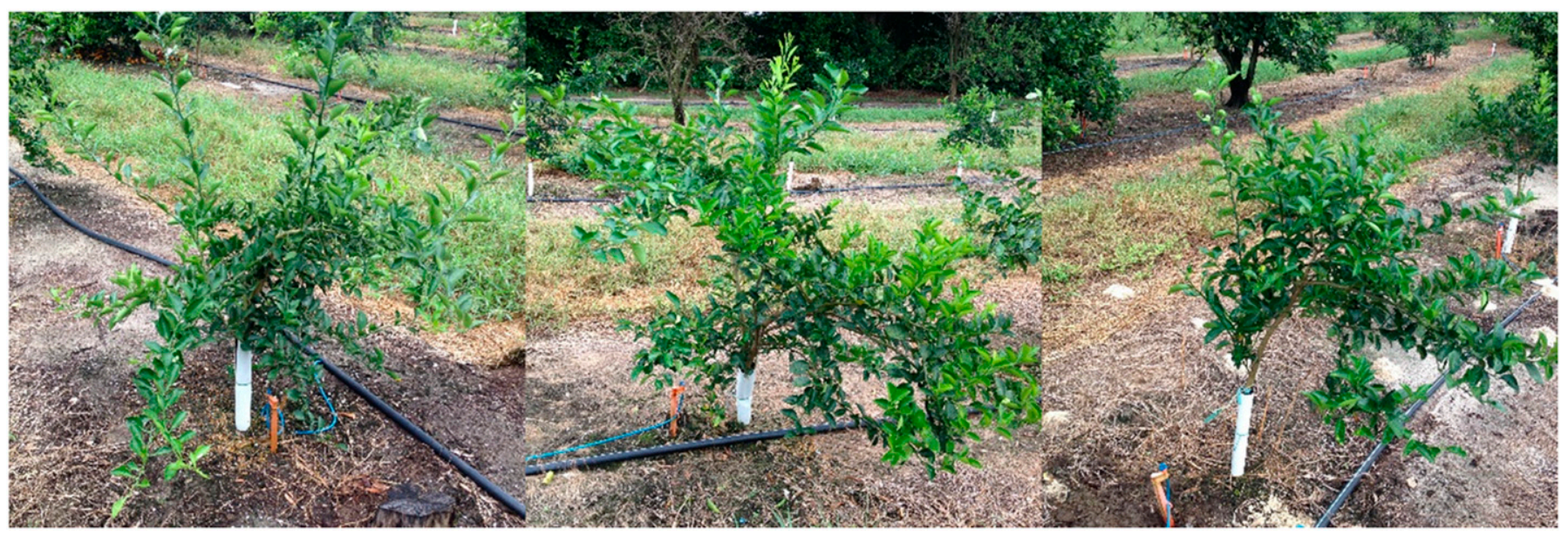

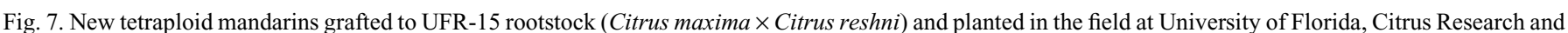
Education Center, Lake Alfred. Left: Somatic hybrid of 'Ponkan' mandarin + 'W. Murcott' tangor; middle: somatic hybrid of 'W. Murcott' + 'Snack' tangor; right: autotetraploid 'W. Murcott'. Trees are just older than 1 year. 
production of plants with desired traits. The reason for the authentication is that ovules and seeds used to generate callus and leaf protoplasts may be of nucellar or zygotic origin, although most citrus genotypes produce nucellar seeds at a very high rate.

In conclusion, we have successfully used protoplast fusion to produce several new allo- and autotetraploids that can be used as breeding parents in future interploid crosses. These new tetraploids are expected to contribute significantly to our future triploid breeding efforts as sources of high fruit quality and the important "easy-peel" characteristics. The tetraploids have been grafted to rootstocks and planted in the field (Fig. 7), where they are now undergoing a natural screen for HLB (Huanglongbing or citrus greening disease) that is now endemic in Florida. Protoclones of 'W. Murcott' have exhibited short juvenility and precocious bearing in our program (J.W. Grosser, unpublished data). Because most of the tetraploids contain precocious 'W. Murcott' genetics, we expect at least some of them to have shorter juvenility than most of our existing somatic hybrids from other parentage, which would accelerate their utility in our breeding program.

\section{Literature Cited}

Aleza, P., J. Cuenca, J. Jaurez, J.A. Pina, and L. Navarro. 2010. 'Garbi' mandarin: A new late-maturing triploid hybrid. HortScience 45:139_ 141.

Aleza, P., A. Garcia-Lor, J. Juarez, and L. Navarro. 2016. Recovery of citrus cybrid plants with diverse mitochondrial and chloroplastic genome combinations by protoplast fusion followed by in vitro shoot, root, or embryo micrografting. Plant Tissue Organ Cult. 126:205-217.

An, H.J., S.B. Jin, B.C. Kang, and H.G. Park. 2008. Production of somatic hybrids between 'Satsuma' mandarin (Citrus unshiu) and 'Navel' orange (Citrus sinensis) by protoplast fusion. J. Plant Biol. 51:186-191.

Chen, C., J.W. Grosser, M. Ćalović, G. Pasquali, J. Gmitter, and F.G. Gmitter, Jr. 2008a. Verification of mandarin and pummelo somatic hybrids by expressed sequence tag-simple sequence repeat marker analysis. J. Amer. Soc. Hort. Sci. 133:794-800.

Chen, C., K.D. Bowman, Y.A. Choi, P.M. Dang, M.N. Rao, S. Huang, J.R. Soneji, T.G. McCollum, and F.G. Gmitter, Jr. 2008b. EST-SSR genetic maps for Citrus sinensis and Poncirus trifoliate. Tree Genet. Genomes 4:1-10.

Chen, C., P. Zhou, Y. Choi, S. Huang, and F.G. Gmitter, Jr. 2006. Mining and characterizing microsatellites from citrus ESTs. Theor. Appl. Genet. 112:1248-1257.

Constabel, F. 1984. Fusion of protoplasts by polyethylene glycol (PEG), p. 414-422. In: I.K. Vasil (ed.). Cell culture and somatic cell genetics of plants, Vol 1. Academic Press, New York, NY.

Cuenca, J., P. Aleza, J. Jaurez, J.A. Pina, and L. Navarro. 2010. 'Safor' mandarin: A new citrus mid-late triploid hybrid. HortScience 45:977-980.

Dudits, D., O. Fejér, G. Hadlaczky, C. Koncz, G. Lázár, and G. Horváth. 1980. Intergeneric gene transfer mediated by protoplast fusion. Mol. Gen. Genet. 179:283-288.

Duncan, D.B. 1955. Multiple ranges and multiple F test. Biometrics $11: 1-42$

Dutt, M., V. Orbovic, and J.W. Grosser. 2009. Cultivar dependent gene transfer into citrus using Agrobacterium. Proc. Florida State Hort. Soc. 122:85-89.

Evans, D.A. and J.E. Bravo. 1983. Protoplast isolation and culture, p. 124-176. In: D.A. Evans, W.R. Sharp, P.V. Ammirato, and Y. Yamada (eds.). Handbook of plant cell culture, Vol 1. Macmillan, New York, NY.
Frost, H.B. and R.K. Soost. 1968. Seed reproduction: Development of gametes and embryos, p. 290-324. In: W. Reuther, H.J. Batchelor, and L.D. Batchelor (eds.). The citrus industry, Vol. 1. Univ. California Press, Berkeley, CA.

Fu, C.H., C.L. Chen, W.W. Guo, and X.X. Deng. 2004. GISH, AFLP and PCR-RFLP analysis of an intergeneric somatic hybrid combining 'Goutou' sour orange and Poncirus trifoliata. Plant Cell Rpt. 23:391-396.

Grosser, J.W. and F.G. Gmitter, Jr. 1990. Protoplast fusion and citrus improvement. Plant Breed. Rev. 8:339-374.

Grosser, J.W. and F.G. Gmitter, Jr. 2011. Protoplast fusion in the production of tetraploids and triploids: Applications in scion and rootstock breeding. Plant Cell Tissue Organ Cult. 104:343-357.

Grosser, J.W., F.A.A. Mourao, F.G. Gmitter, Jr., E.S. Louzada, J. Jiang, K. Baergen, A. Quiros, C. Cabasson, J.L. Schell, and J.L. Chandler. 1996. Allotetraploid hybrids between citrus and seven related genera produced by somatic hybridization. Theor. Appl. Genet. 92:577-582.

Grosser, J.W., F.G. Gmitter, Jr., E.S. Louzada, and J.L. Chandler. 1992a. Production of somatic hybrid and autotetraploid breeding parents for seedless citrus development. HortScience 27:1125-1127. Grosser, J.W., F.G. Gmitter, Jr., F. Sesto, X.X. Deng, and J.L. Chandler. 1992b. Six new somatic citrus hybrids and their potential for cultivar improvement. J. Amer. Soc. Hort. Sci. 117:169-173.

Grosser, J.W., H.J. An, M. Ćalović, D.H. Lee, C. Chen, M. Vasconcellos, and F.G. Gmitter, Jr. 2010a. Production of new allotetraploid and autotetraploid citrus breeding parents: Focus on zipperskin mandarins. HortScience 45:1160-1163.

Grosser, J.W., M. Ćalović, and E.S. Louzada. 2010b. Protoplast fusion technology - somatic hybridization and cybridization, p. 175-198. In: M.R. Davey and P. Anthony (eds.). Plant cell culture - Essential methods (methods and protocols). Agritech Publ., Shrub Oak, NY.

Grosser, J.W., P. Ollitrault, and O. Olivares-Fuster. 2000. Somatic hybridization in citrus: An effective tool to facilitate variety improvement. In Vitro Cell. Dev. Biol. Plant 36:434-449.

Guo, W.W., D. Prasad, P. Serrano, F.G. Gmitter, Jr., and J.W. Grosser. 2004. Citrus somatic hybridization with potential for direct tetraploid scion cultivar development. J. Hort. Sci. Biotechnol. 79:400405.

Guo, W.W., Y.J. Cheng, C.L. Chen, and X.X. Deng. 2006. Molecular analysis revealed autotetraploid, diploid and tetraploid cybrid plants regenerated from an interspecific somatic fusion in Citrus. Scientia Hort. 108:162-166.

Guo, W.W., X.K. Dong, W.X. Meng, X.Z. Zhou, X. Qiang, and X.X. Deng. 2018. Ploidy manipulation via cell engineering for citrus improvement facilitated by application of molecular markers. Acta Hort. 1203:105-109.

Louzada, E.S., J.W. Grosser, and F.G. Gmitter, Jr. 1993. Intergeneric somatic hybridization of sexually incompatible parents - Citrus sinensis and Atalantia ceylanica. Plant Cell Rpt. 12:687-690.

Mendes-da-Gloria, F.J., F.A.A. Mourao, and B.M.J. Mendes. 2000. Plant regeneration from protoplast of Brazilian citrus cultivars. Pesqui. Agropecu. Bras. 35:727-732.

Ollitrault, P., W.W. Guo, and J.W. Grosser. 2007. Recent advances and evolving strategies in citrus somatic hybridization, p. 235-260. In: I.H. Kahn (ed.). Citrus genetics, breeding and biotechnology. CAB Intl., Wallingford, UK.

Prakash, J. and M.J. Foxe. 1984. Use of cellulase Onozuka RS and Pectolyase Y-23 in isolating leaf mesophyll protoplasts from two recalcitrant potato cultivars. Irish J. Agr. Res. 23:99-103.

Scarano, M.T., L. Abbate, S. Ferrante, S. Lucretti, and N. Tusa. 2002. ISSR-PCR technique: A useful method for characterizing new allotetraploid somatic hybrids of mandarin. Plant Cell Rpt. 20:1162-1166.

Soost, R.K. and J.W. Cameron. 1980. 'Oroblanco' a triploid pummelo-grapefruit hybrid. HortScience 15:667-669.

Soost, R.K. and J.W. Cameron. 1985. 'Melogold' a triploid pummelograpefruit hybrid. HortScience 20:1134-1135. 
Soost, R.K. and M.L. Roose. 1996. Citrus, p. 257-323. In: J. Janick and J.N. Moore (eds.). Fruit breeding: Tree and tropical fruits, Vol. 1. Wiley, New York, NY.

Starrantino, A. 1999. Tacle, a new triploid Clementine $\times$ Tarocco hybrid. Rivista di Fruiticoltura c di Ortofloricoltura 61:45-47.

Starrantino, A. and P. Caponnetto. 1990. Effect of cytokinins in embryogenic callus formation from undeveloped ovules of orange. Acta Hort. 280:191-194.

Tomaz, M.L., B.M.J. Mendes, F.A.A. Mourao, C.G.B. Demetrio, N. Jansakul, and A.P.M. Rodriguez. 2001. Somatic embryogenesis in
Citrus spp.: Carbohydrate stimulation and histodifferentiation. In Vitro Cell. Dev. Biol. Plant 37:446-452.

Tusa, N., J.W. Grosser, F.G. Gmitter, Jr., and E.S. Louzada. 1992. Production of tetraploid somatic hybrid breeding parents for use in lemon cultivar improvement. HortScience 27:445447.

$\mathrm{Xu}, \mathrm{X}$., J. Lu, J.W. Grosser, and P. Cousins. 2007. Isolation and culture of grape protoplasts from somatic embryogenic suspension cultures and leaves of Vitis vinifera and Vitis rotundifolia. Acta Hort. 738:787-790. 